\title{
Effect of Heat Source/Sink on Free Connective MHD Flow past an Exponentially Accelerated Infinite Plate with Mass Diffusion and Chemical Reaction
}

\author{
Shipra, B. P. Garg
}

\begin{abstract}
The effects of heat source/sink and chemical reaction with mass diffusion on free convective incompressible viscous fluid flow past an accelerated vertical plate with magnetic field has been investigated. Laplace transformation method has been applied to solve the system of linear partial differential equations. The result is presented in form of complementary error function and exponential function. The effect of non dimensional parameters such as Schmidt number (Sc), Accelerated parameter (a), Chemical reaction parameter $(K)$, Prandtl number (Pr), Magnetic field parameter (M), Mass Grashof number (Gm), Heat source/sink parameter $(H)$, Thermal Grashof number (Gr) on temperature, concentration, velocity has been discussed with graphs.
\end{abstract}

Index Terms: Free-convection, Mass transfer, MHD, Heat Source/Sink, Chemical Reaction.

\section{INTRODUCTION}

The study of free convective flows under different boundary conditions has caught the attention of various researchers and scientists now a days because of its large number of applications in the various fields like science, environment, engineering and technology etc. This study is also important for many industrial and manufacturing processes like designing of apparatus for nuclear power plant, various devises of propulsion for space vehicles, gas turbines, satellites, missiles and aircrafts etc. Chemical reaction effect combined with heat and mass transfer is important in chemical industries. The magnetic field effect on natural convective flows is useful in ionized gases and liquid metals. The study of collective heat and mass transfer effect has applications in fluid boiling and condensing at a solid surface, flow of air in a desert cooler, drying etc. The study of fluid flows with radiations is important for many

\footnotetext{
Manuscript Received On June 15, 2019

B. P. Garg, Research Supervisor, IKG Punjab Technical University, Jalandhar.

Shipra, Research Scholar, IKG Punjab Technical University, Jalandhar.
}

industrial and environment processes.

Many researchers have made a contribution to find the exact solution of free convective flow problems with special boundary conditions using various methods. Stokes [1] made the first contribution by solving the flow problem related the viscous incompressible fluid. The study of chemical reaction and thermal radiation effects can be seen in the work of researchers like Raptis and Massalas [2], Muthucumaraswamy and Ganesan [3].

The researchers such as Soundalgekar et al. [5], Singh and Kumar [6], Muthucumaraswamy and Visalakshi [7] etc. have made contribution in solving flow problems related to the heat and mass transfer effect of free convective flow with different conditions as constant mass flux, with uniform mass diffusion, exponentially accelerated vertical plate, the effect of heat sources, with transverse magnetic field, with vertical stretching surface etc.

Hossain et al. [8], Hady et al. [9], Garg et al. [10] etc have studied the heat generation/absorption effect with different flow conditions.

The present investigation aims to study the combined effect of heat source/sink, mass diffusion and chemical reaction on free convective unsteady fluid flow.

\section{MATHEMATICAL ANALYSIS}

We are considering viscous incompressible fluid flow past an exponentially accelerated vertical plate. The $\boldsymbol{x}^{f}$-axis is chosen along the plate in vertically up direction and $y^{\prime}$-axis is chosen perpendicular to it. At time $\mathrm{t}^{t} \leq 0$, the fluid and plate are kept at equal temperature in fixed condition. At time $t^{t}>0$, the plate is exponentially accelerated with velocity $\mathrm{u}=\mathrm{u}_{0} \mathrm{e}^{\mathrm{at} \mathrm{t}^{x}}$. The temperature and concentration of plate is slightly increased to $\mathrm{T}_{\mathrm{w}}{ }^{\prime}$ and $\mathrm{C}_{\mathrm{w}}{ }^{\prime}$. The flow field is governed by the following set of equations:

Published By:

Blue Eyes Intelligence Engineering

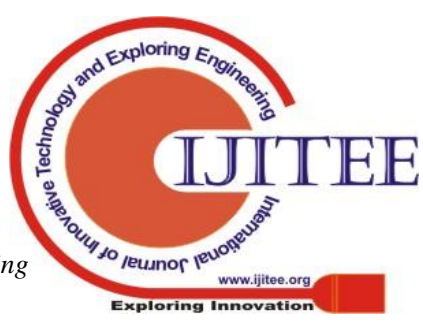




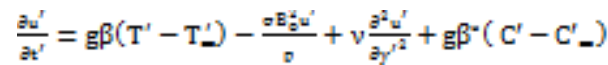

$\mathrm{Pc}_{\mathrm{p}} \frac{\partial \mathrm{T}^{v}}{\partial \mathrm{t}^{s}}=\mathrm{k} \frac{\partial^{\mathrm{z}} \mathrm{T}^{v}}{\partial \mathrm{y}^{2}}+\mathrm{Q}^{*}\left(\mathrm{~T}^{s}-\mathrm{T}_{\mathrm{se}}^{s}\right)$

$\frac{\partial C y}{\partial t}=\mathbb{D} \frac{\partial^{2} C_{y}^{y}}{\partial y^{\prime 2}}+K_{1}\left(C^{y}-C_{m}^{y}\right)$

The boundary conditions are

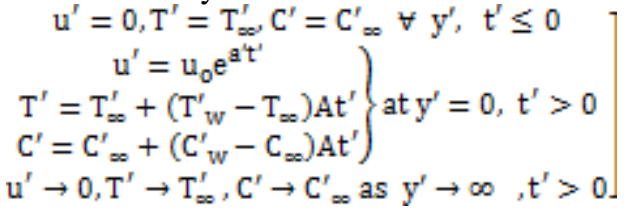

Where $\mathrm{A}=\mathrm{u}_{\mathrm{o}}{ }^{2} / 2$

Here $\mathrm{u}^{t}$ is velocity in $\mathrm{x}^{t}$ direction, $\mathrm{t}^{t}$ is time, $\mathrm{T}^{s}$ is fluid temperature, $\mathrm{T}_{\mathrm{w}}^{s}$ is the plate temperature, $\mathrm{C}^{f}$ is species concentration, $\mathrm{T}_{\mathrm{m}}^{g}$ is fluid temperature away from plate, $\mathrm{g}$ is acceleration due to gravity, $C_{w}^{y}$ is the species concentration near wall, $\mathrm{C}_{\mathrm{se}}^{y}$ is species concentration far away from plate, $\beta$ is the coefficient of volume expansion, $\beta^{*}$ is the thermal expansion coefficient with concentration, $\sigma$ is electrical conductivity of the fluid, $v$ is the kinematic viscosity, $P$ is the density, $B_{0}$ is electromagnetic induction, $\mathrm{c}_{\mathrm{p}}$ is specific heat at constant pressure, $\mathrm{k}$ is thermal conductivity, $\mathrm{K}_{\mathrm{I}}$ is reaction rate constant, $\mathrm{Q}^{*}$ is heat source/sink and D is chemical molecular diffusivity .

Introducing following non- dimensional quantities:

$$
\begin{aligned}
& \mathrm{u}=\frac{\mathrm{u} y}{\mathrm{u}_{0}} \quad \mathrm{y}=\frac{\mathrm{y}^{y}}{\mathrm{v}} \mathrm{u}_{0} \quad \mathrm{t}=\frac{\mathrm{tru}_{0}^{2}}{\mathrm{v}} \quad \mathrm{a}=\frac{\mathrm{a} \mathrm{w}^{2}}{\mathrm{u}_{0}^{2}} \\
& \theta=\frac{\left(\mathrm{T}^{s}-\mathrm{T}_{\mathrm{we}}^{s}\right)}{\left(\mathrm{T}_{\mathrm{w}}^{s}-\mathrm{T}_{\mathrm{we}}^{s}\right)} \quad \mathrm{C}=\frac{\left(\mathrm{C}^{y}-\mathrm{C}_{\mathrm{we}}^{s}\right)}{\left(\mathrm{C}_{\mathrm{w}}^{s}-\mathrm{C}_{\mathrm{ws}}^{s}\right)} \\
& \mathrm{G}_{\mathrm{r}}=\frac{\mathrm{vg} \beta\left(\mathrm{T}_{\mathrm{w}}^{v}-\mathrm{T}_{\mathrm{wa}}^{v}\right)}{\mathrm{u}_{\mathrm{a}}^{\mathrm{a}}}, \mathrm{G}_{\mathrm{m}}=\frac{\mathrm{vg} \beta^{*}\left(\mathrm{C}_{\mathrm{w}}^{v}-\mathrm{C}_{\mathrm{wa}}^{v}\right)}{\mathrm{u}_{0}^{\mathrm{a}}} \\
& \mathrm{M}=\frac{\sigma \mathrm{B}_{\mathrm{a}}^{2} \mathrm{v}}{\mathrm{pu} \mathrm{u}_{\mathrm{a}}^{2}} \quad \mathrm{P}_{\mathrm{r}}=\frac{\mathrm{wpc}_{\mathrm{p}}}{\mathrm{k}} \quad \mathrm{S}_{\mathrm{c}}=\frac{\mathrm{w}}{\mathrm{D}} \quad \mathrm{K}=\frac{\mathrm{wK}_{\mathrm{I}}}{\mathrm{u}_{\mathrm{\sigma}}^{2}} \quad \mathrm{H}=\frac{\mathrm{Q}^{*} \mathrm{v}^{2}}{\mathrm{ku} \mathrm{u}_{\mathrm{a}}^{2}}
\end{aligned}
$$

Where a, H, M, $\theta, \mathrm{Sc}, \operatorname{Pr}, \mathrm{G}_{\mathrm{r}}, \mathrm{G}_{\mathrm{m}}$, and $\mathrm{K}$ are Accelerated parameter, Heat source/sink parameter, Magnetic field parameter, dimensionless temperature, Schmidt number, Prandtl number, Thermal Grashof

number, Mass Grashof number and Chemical reaction parameter respectively.

Then in view of (5), equations (1), (2) and (3) reduce to

$$
\frac{\partial u}{\partial t}=\frac{\partial^{2} u}{\partial y^{2}}+G_{r} \theta+G_{m} C-M u
$$

$\mathrm{P}_{\mathrm{r}} \frac{\partial \theta}{\partial \mathrm{t}}=\frac{\partial^{2} \theta}{\partial y^{2}}-\mathrm{H \theta}$

$\mathrm{S}_{\mathrm{c}} \frac{\partial \mathrm{C}}{\partial \mathrm{t}}=\frac{1}{\mathrm{~S}_{\mathrm{c}}} \frac{\partial^{2} \mathrm{C}}{\partial y^{2}}-\mathrm{KC}$

The corresponding boundary conditions becomes $u(y, t)=0, \theta(y, t)=0, C(y, t)=0 \forall y$ and $t \leq 0$ $u\left(y_{v} t\right)=e^{a t}{ }_{x} \theta\left(y_{x} t\right)=t_{v} C\left(y_{x} t\right)=t$

for $y=0$ and $t>0$ $u\left(y_{v} t\right) \rightarrow 0_{v} \quad \theta\left(y_{v} t\right) \rightarrow 0_{v} C\left(y_{v} t\right) \rightarrow 0$ as $y \rightarrow \infty$ and $t>0$ (9)

The system of equations (6)-(8), under the boundary conditions (9) represents the proposed flow problem.

\section{SOLUTION OF THE PROBLEM}

We have used Laplace Transformation method to find the solution of the equations of flow (6)-(8), under the boundary conditions (9). The solution of given problem for temperature, concentration and velocity are given by $\theta(y, t)=C_{9} \exp \left(\alpha_{5}\right) \operatorname{erfc}\left(\beta_{9}\right)+C_{4} \exp \left(-\alpha_{5}\right) \operatorname{erfc}\left(\beta_{10}\right)$

$$
\mathrm{C}(\mathrm{y}, \mathrm{t})=\mathrm{C}_{5} \exp \left(\alpha_{7}\right) \operatorname{erfc}\left(\beta_{13}\right)+\mathrm{C}_{6} \exp \left(-\alpha_{7}\right) \operatorname{erfc}\left(\beta_{14}\right)
$$

$\mathrm{u}(\mathrm{y}, \mathrm{t})=\frac{1}{2} \exp \left(\gamma_{1}\right)\left[\exp \left(\alpha_{1}\right) \operatorname{erfc}\left(\beta_{1}\right)+\exp \left(-\alpha_{1}\right) \operatorname{erfc}\left(\beta_{2}\right)\right]-$

$\left(\mathbb{U}_{1}+\mathbb{U}_{2}\right)\left[\exp \left(\alpha_{2}\right) \operatorname{erfc}\left(\beta_{3}\right)+\exp \left(-\alpha_{2}\right) \operatorname{erfc}\left(\beta_{4}\right)\right]-$

$\left(\mathbb{U}_{3}+\mathbb{U}_{4}\right)\left[C_{1} \exp \left(\alpha_{2}\right) \operatorname{erfc}\left(\beta_{2}\right)+C_{2} \exp \left(-\alpha_{2}\right) \operatorname{erfc}\left(\beta_{4}\right)\right]+$

$\mathbb{U}_{1} \exp \left(\gamma_{2}\right)\left[\exp \left(\alpha_{2}\right) \operatorname{erfc}\left(\beta_{5}\right)+\exp \left(-\alpha_{7}\right) \operatorname{erfc}\left(\beta_{6}\right)\right]+$

$\mathrm{U}_{2} \exp \left(\mathrm{Y}_{a}\right)\left[\exp \left(\alpha_{4}\right) \operatorname{erfc}\left(\beta_{7}\right)+\exp \left(-\alpha_{4}\right) \operatorname{erfc}\left(\beta_{8}\right)\right]+$

$\mathbb{U}_{1}\left[\exp \left(\alpha_{5}\right) \operatorname{erfc}\left(\beta_{9}\right)+\exp \left(-\alpha_{5}\right) \operatorname{erfc}\left(\beta_{10}\right)\right]+$

$\mathbb{U}_{2}\left[C_{9} \exp \left(\alpha_{5}\right) \operatorname{erfc}\left(\beta_{9}\right)+C_{4} \exp \left(-\alpha_{5}\right) \operatorname{erfc}\left(\beta_{10}\right)\right]-$

$\mathbb{U}_{1} \exp \left(\gamma_{2}\right)\left[\exp \left(\alpha_{6}\right) \operatorname{erfc}\left(\beta_{11}\right)+\exp \left(-\alpha_{6}\right) \operatorname{erfc}\left(\beta_{12}\right)\right]+$

$\mathbb{U}_{4}\left[\mathrm{C}_{5} \exp \left(\alpha_{7}\right) \operatorname{erfc}\left(\beta_{12}\right)+\mathrm{C}_{6} \exp \left(-\alpha_{7}\right) \operatorname{erfc}\left(\beta_{14}\right)\right]+$

$\mathrm{U}_{2}\left[\exp \left(\alpha_{7}\right) \operatorname{erfc}\left(\beta_{19}\right)+\exp \left(-\alpha_{7}\right) \operatorname{erfc}\left(\beta_{14}\right)\right]$

$-\mathrm{U}_{2}\left[\exp \left(\alpha_{9}\right) \operatorname{erfc}\left(\beta_{15}\right)+\exp \left(-\alpha_{g}\right) \operatorname{erfc}\left(\beta_{16}\right)\right]$

\section{NUSSELT NUMBER}

Nusselt number is given by

$$
\begin{aligned}
& \mathrm{N}_{\mathrm{u}}=-\left(\frac{\partial \mathrm{B}(\mathrm{Qu} t)}{\partial \mathrm{t}}\right)_{\mathrm{y}=0} \\
& \quad\left(\mathrm{t} \sqrt{\mathrm{H}}+\frac{\mathrm{P}_{\mathrm{r}}}{2 \sqrt{\mathrm{H}}}\right) \operatorname{erf} \sqrt{\frac{\mathrm{H}}{\mathrm{P}_{\mathrm{r}}}} \mathrm{t}+\sqrt{\frac{\mathrm{tP}_{\mathrm{r}}}{\pi}} \exp \left(-\frac{\mathrm{H}}{\mathrm{P}_{\mathrm{r}}} \mathrm{t}\right) .
\end{aligned}
$$

\section{SHERWOOD NUMBER}

Sherwood number is given by

$$
\begin{aligned}
& \mathrm{S}_{\mathrm{h}}=-\left(\frac{\partial \mathrm{C}(\mathrm{gt} \mathrm{t})}{\partial \mathrm{t}}\right)_{\mathrm{y}=0} \\
& =\frac{1}{2} \sqrt{\frac{S_{c}}{K}} \operatorname{erf} \sqrt{K t}+t \sqrt{k S_{c}} \operatorname{erf} \sqrt{K t}+\sqrt{\frac{t S_{c}}{\pi}} \exp (-k t)
\end{aligned}
$$

\section{SKIN- FRICTION}

Skin-Friction is given by

$$
\tau=-\left(\frac{\partial u(y: t)}{\partial t}\right)_{y=0}
$$

Published By:

Blue Eyes Intelligence Engineering

\& Sciences Publication 


$$
\begin{aligned}
& =\exp (\mathrm{at}) \sqrt{\mathrm{M}+\mathrm{a}} \operatorname{erf} \sqrt{(\mathrm{M}+\mathrm{a})} \mathrm{t}+[1- \\
& \left.\left(\mathrm{U}_{\mathrm{a}}+\mathrm{U}_{4}\right) \mathrm{t}\right] \sqrt{\frac{1}{\pi \mathrm{t}}} \exp (-\mathrm{Mt})+ \\
& \mathrm{U}_{\mathrm{a}}\left[\sqrt{\frac{\mathrm{tP}_{\mathrm{r}}}{\pi}} \exp \left(-\frac{\mathrm{H}}{\mathrm{P}_{\mathrm{r}}} \mathrm{t}\right)+\left(\mathrm{t} \sqrt{\mathrm{H}}+\frac{\mathrm{P}_{\mathrm{r}}}{2 \sqrt{\mathrm{H}}}\right) \operatorname{erf} \sqrt{\frac{\mathrm{H}}{\mathrm{P}_{\mathrm{r}}} \mathrm{t}}-\right. \\
& \left.\left(\frac{1}{2 \sqrt{M}}+t \sqrt{\mathrm{M}}\right) \operatorname{erf} \sqrt{\mathrm{Mt}}\right]+\mathrm{U}_{4}\left[\frac{1}{2} \sqrt{\frac{S_{c}}{K}} \operatorname{erf} \sqrt{\mathrm{Kt}}+\right. \\
& \mathrm{t} \sqrt{\mathrm{KS}_{\mathrm{c}}} \operatorname{erf} \sqrt{\mathrm{Kt}}+\sqrt{\frac{\mathrm{tS_{c }}}{\pi}} \exp (-\mathrm{kt})-\left(\frac{1}{2 \sqrt{\mathrm{M}}}+\right. \\
& \mathrm{t} \sqrt{\mathrm{M}}) \operatorname{erf} \sqrt{\mathrm{Mt}}]+ \\
& 2 \mathrm{U}_{1}\left[\exp (\mathrm{lt}) \sqrt{\mathrm{M}+\mathrm{I}} \operatorname{erf} \sqrt{(\mathrm{M}+1)} \mathrm{t}+\sqrt{\mathrm{H}} \operatorname{erf} \sqrt{\frac{\mathrm{H}}{\mathrm{P}_{\mathrm{r}}}} \mathrm{t}-\right. \\
& \left.\exp (\mathrm{lt}) \sqrt{\mathrm{H}+\mathrm{IP}_{\mathrm{r}}} \operatorname{erf} \sqrt{\left(\mathrm{H}+\mathrm{IP}_{\mathrm{r}}\right) t}-\sqrt{\mathrm{M}} \operatorname{erf} \sqrt{\mathrm{Mt}}\right]+ \\
& 2 \mathrm{U}_{2}[\exp (\mathrm{mt}) \sqrt{\mathrm{M}+\mathrm{m}} \operatorname{erf} \sqrt{(\mathrm{M}+\mathrm{m})} \mathrm{t}+ \\
& \sqrt{\mathrm{KS}_{\mathrm{c}}} \operatorname{erf} \sqrt{\mathrm{Kt}}-\sqrt{(\mathrm{K}+\mathrm{m}) \mathrm{S}_{\mathrm{c}}} \operatorname{erf} \sqrt{(\mathrm{K}+\mathrm{m}) \mathrm{t}}+ \\
& \left.\sqrt{\mathrm{KS}_{\mathrm{c}}} \operatorname{erf} \sqrt{\mathrm{Kt}}-\sqrt{\frac{\mathrm{S}_{\mathrm{c}}}{\pi t}} \exp (-(\mathrm{k}+\mathrm{m}) \mathrm{t})-\sqrt{\mathrm{M}} \operatorname{erf} \sqrt{\mathrm{Mt}}\right]
\end{aligned}
$$

\section{RESULTS AND DISCUSSIONS}

To identify with the physical properties of the problem, algebraic calculations are carried out to demonstrate the effect of various parameters upon the characteristics of flow. The algebraic values of temperature, concentration, velocity are calculated at flow parameters like Prandtl number (Pr), Accelerated parameter (a), Chemical reaction parameter $(\mathrm{K})$, Thermal Grashof number (Gr), Schmidt number (Sc), Mass Grashof number $(\mathrm{Gm})$, Heat source/sink parameter $(\mathrm{H})$, Magnetic field parameter (M) and Time (t). These results are shown graphically by Figs. (1) - (11).

Effects of $\mathrm{H}$, Pr and t on temperature profile are shown in Fig.1. Here different values of $\mathrm{H}$ are chosen 2, 4 and 6 to show the effect of it on temperature .The value of $\operatorname{Pr}=0.71$ and $\mathrm{t}=0.2$ are taken as constant. It is observed that higher values of $\mathrm{H}$ decrease the fluid temperature. The cause of $\mathrm{t}$ on temperature is shown by taking values of $\mathrm{t}$ as $0.2,0.4$ and 0.6 with fixed values of $\mathrm{H}=2$ and $\mathrm{Pr}=0.71$. The graph depicts that temperature rises with time.

Different values of $\operatorname{Pr}$ are taken as $0.21,0.71$ and 7 with fixed values of $H=2$ and $t=0.2$. From the graph, it is observed that temperature reduces when Prandtl number increases. It is also noticed that temperature for air is high as compared to temperature for water.

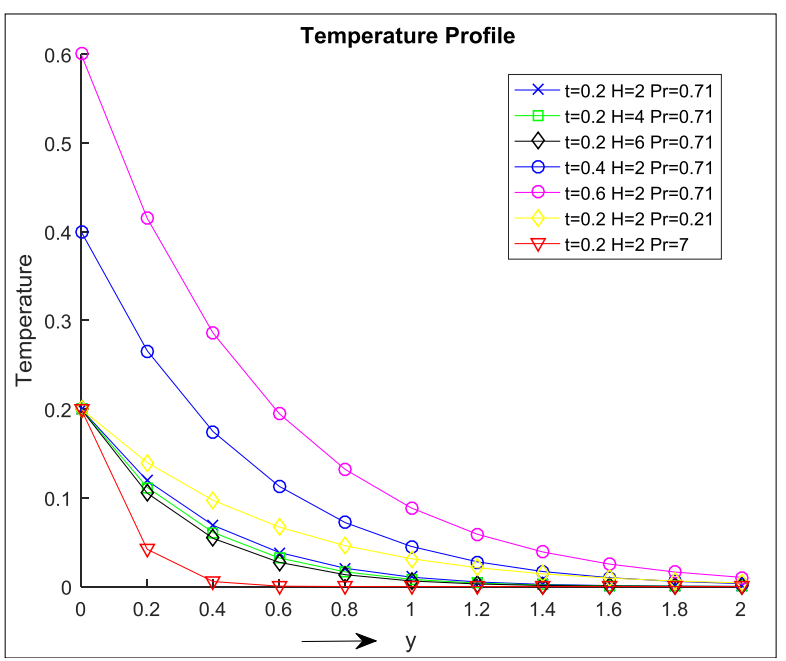

Fig.1 Temperature profile for values of $\mathrm{H}, \mathrm{t}$ and $\mathrm{Pr}$ Fig. 2 illustrates the concentration profile at $\mathrm{t}, \mathrm{K}$ and Sc. The values of $\mathrm{K}$ are taken as 3, 5 and 7 keeping $\mathrm{t}=0.2$ and $\mathrm{Sc}=2.01$ as constants. The

effect of Schmidt number is presented by taking values as 2.01, 3 and 4 keeping $\mathrm{t}=0.2$ and $\mathrm{K}=3$ fixed. The graph of concentration shows that concentration of plate decreases slightly with higher value of Chemical reaction parameter and Schmidt number. Effect of $t$ is shown by taking values of $\mathrm{t}$ as $0.1,0.20 .3$ and 0.4 keeping $\mathrm{K}=3$ and $\mathrm{Sc}=2.01$ fixed. The graph of concentration shows that concentration of plate increases when time is increased.

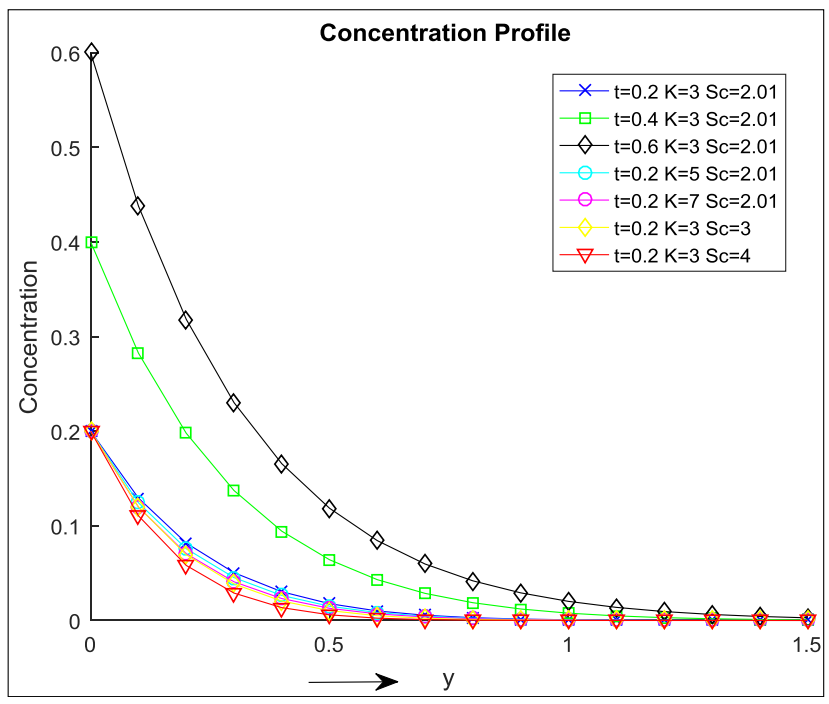

Fig. 2 Concentration profile for different values of $\mathrm{t}, \mathrm{K}$ and $\mathrm{Sc}$

Published By:

Blue Eyes Intelligence Engineering 


\section{EFFECT OF HEAT SOURCE/SINK ON OF MHD FREE CONVECTIVE FLOW PAST AN EXPONENTIALLY ACCELERATED INFINITE VERTICAL PLATE WITH MASS DIFFUSION AND CHEMICAL REACTION}

Effects of various parameters on velocity profile are shown by Figs. (3) - (6). Fig. 3 shows the effect $\mathrm{H}$ and a on velocity Profile. The different values of a are chosen as $0.2,0.4,0.6$ and 0.8. Other parameters $(\mathrm{t}=0.2, \mathrm{H}=2, \mathrm{Sc}=0.60, \mathrm{~K}=3, \mathrm{Gr}=5$, $\mathrm{M}=0.5, \mathrm{Gm}=5, \mathrm{Pr}=0.71$ ) are kept constant. The different values of $\mathrm{H}$ are chosen as $2,4,6$ and 8 . Other parameters $(\mathrm{a}=0.2, \mathrm{t}=0.2, \mathrm{Sc}=0.60, \mathrm{~K}=3, \mathrm{Gr}=5, \mathrm{M}=0.5, \mathrm{Gm}=5, \mathrm{Pr}=0.71)$ are kept constant. The graph depicts that increasing value of accelerated parameter accelerate the fluid flow and increasing values of $\mathrm{H}$ retards the fluid flow.

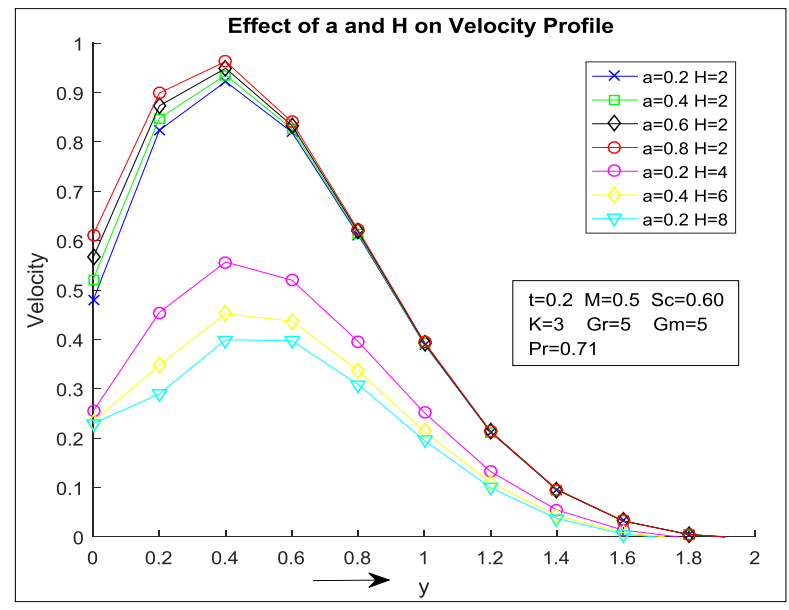

Fig.3 Velocity profile for different values of $\mathrm{H}$ and a

The effect of Pr and Sc are shown graphically by Fig. 4. The different values of $\operatorname{Pr}$ are chosen as $0.16,0.21$ and 0.71 . Other parameters $(\mathrm{t}=0.2, \mathrm{a}=0.2, \mathrm{H}=4, \mathrm{M}=0.5, \mathrm{Sc}=0.60, \mathrm{~K}=5$, $\mathrm{Gr}=5, \mathrm{Gm}=5$ ) are kept constant. The values of $\mathrm{Sc}$ are chosen as 0.60 (for Water), 0.75 (for Oxygen) and 0.78 (for Ammonia). Other parameters $(\mathrm{t}=0.2, \mathrm{a}=0.2, \mathrm{H}=4, \mathrm{M}=0.5$, $\mathrm{K}=5, \mathrm{Gr}=5, \mathrm{Gm}=5, \mathrm{Pr}=0.71$ ) are kept constant. It is noticed motion of fluid slow down with increasing values of Pr or Sc. It means thermal diffusion and mass diffusion accelerate the fluid flow.

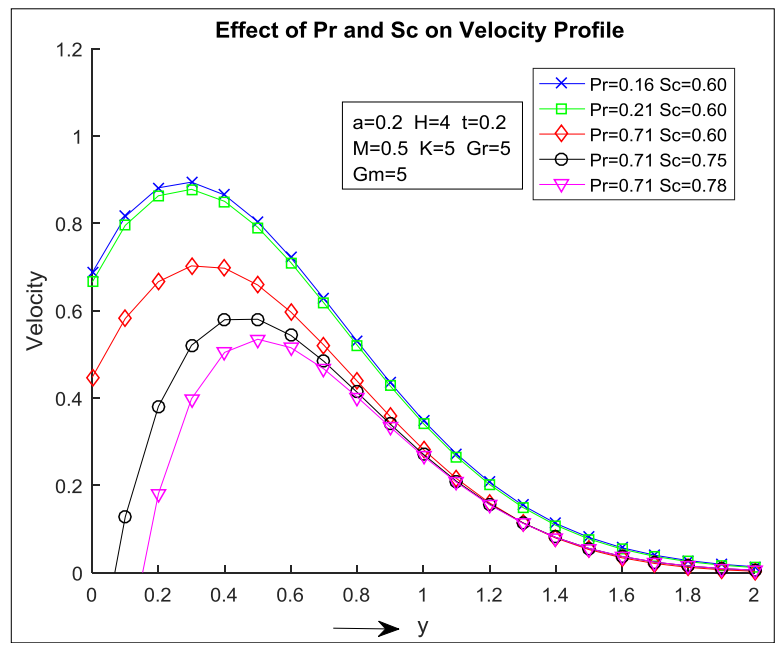

Fig.4 Velocity profile for different values Pr and Sc
Fig. 5 shows the effect $\mathrm{M}$ and $\mathrm{K}$ on velocity Profile. The different values of $\mathrm{M}$ are chosen as $0.5,0.7$ and 1 keeping other parameters $(\mathrm{a}=0.2, \mathrm{t}=0.2, \mathrm{H}=4, \mathrm{Sc}=0.60, \mathrm{~K}=5, \mathrm{Gr}=5$, $\mathrm{Gm}=5, \operatorname{Pr}=0.71$ ) as constant. It is observed that motion of fluid slow down with increasing values of $M$. It means induced magnetic field retards the fluid flow. The different values of $\mathrm{K}$ are chosen as 5,7 and 9. Other parameters $(\mathrm{a}=0.2, \mathrm{t}=0.2, \mathrm{H}=4, \mathrm{Sc}=0.60, \mathrm{Gr}=5, \mathrm{M}=0.5, \mathrm{Gm}=5, \mathrm{Pr}=0.71$ ) are kept constant. The graph depicts that increasing values of $\mathrm{K}$ results in decreasing value of velocity. It means chemical reaction rate slow down the fluid flow.

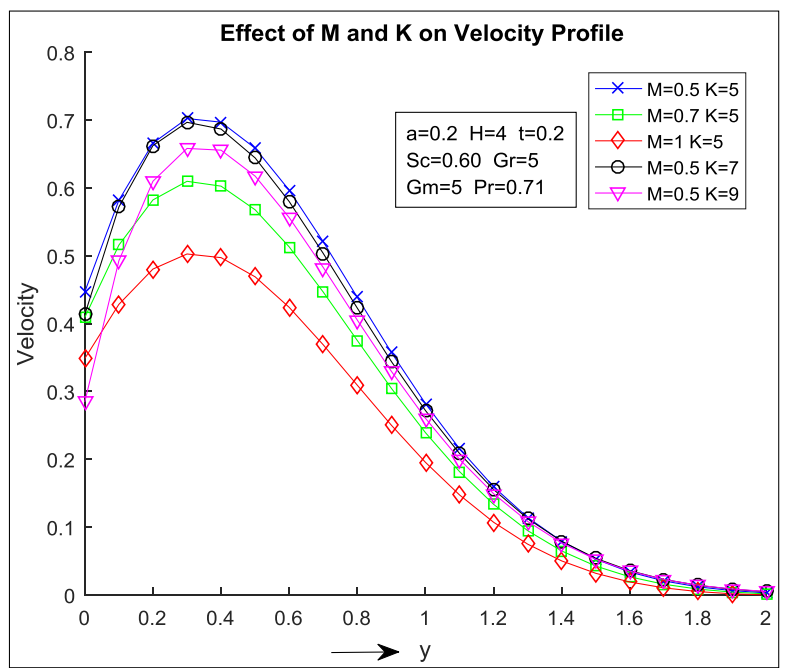

Fig.5 Velocity profile at various values of $\mathrm{M}$ and $\mathrm{K}$

Fig. 6 represents the velocity variations at values of $\mathrm{Gr}$ and $\mathrm{Gm}$. The values of $\mathrm{Gr}$ are chosen as 5, 10 and 15 . Other parameters $(\mathrm{a}=0.2, \mathrm{t}=0.2, \mathrm{H}=4, \mathrm{M}=0.5, \mathrm{Sc}=0.60, \mathrm{~K}=5$, $\mathrm{Gm}=5, \mathrm{Pr}=0.71$ ) are kept constant. It is observed that increasing values of $\mathrm{Gr}$ increases the fluid flow. The different values of $\mathrm{Gm}$ are chosen as 5, 10 and 15 . Other parameters $(\mathrm{a}=0.2, \mathrm{t}=0.2, \mathrm{H}=4, \mathrm{M}=0.5, \mathrm{Sc}=0.60, \mathrm{~K}=5, \mathrm{Gr}=5, \mathrm{Pr}=0.71$ ) are kept constant. It is noticed that velocity decreases by increasing values of Gr but after some distance it starts arising.

The effect of $\mathrm{t}, \mathrm{H}$ and $\mathrm{Pr}$ on Nusselt number is depicted by Fig. 7.The graph indicates that heat transfer rate is higher by increasing values of $\mathrm{t}, \mathrm{H}$ and $\mathrm{Pr}$.

The effect of $\mathrm{t}, \mathrm{K}$ and Sc on Sherwood number is by Fig. 8 . The graph clearly shows that mass transfer rate is higher by increasing values of $\mathrm{t}, \mathrm{K}$ and Sc.

Published By:

Blue Eyes Intelligence Engineering 


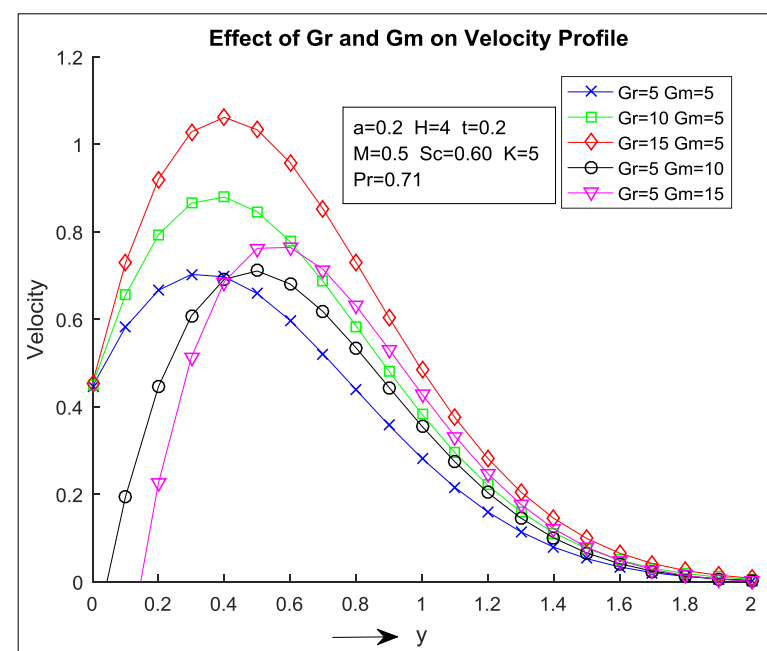

Fig.6 Velocity profile for different values $\mathrm{Gr}$ and $\mathrm{Gm}$

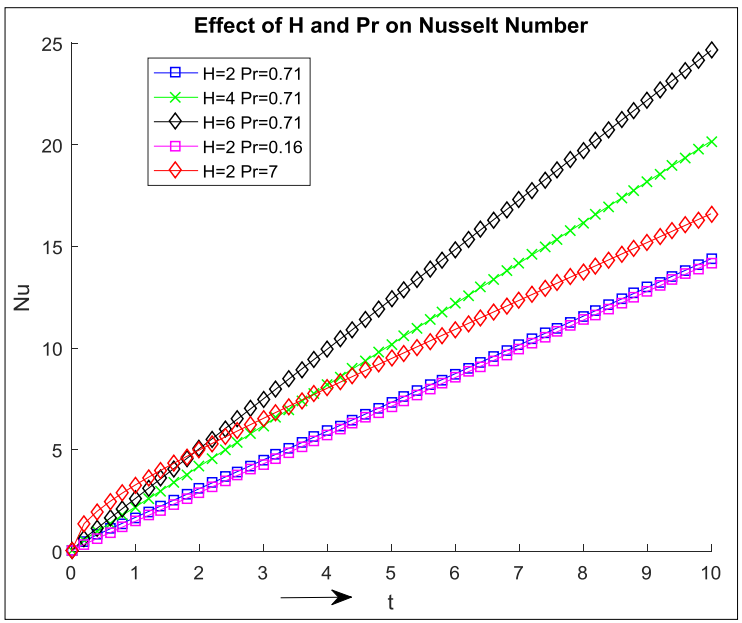

Fig.7 Effect of $\mathrm{H}$ and Pr on Nusselt Number

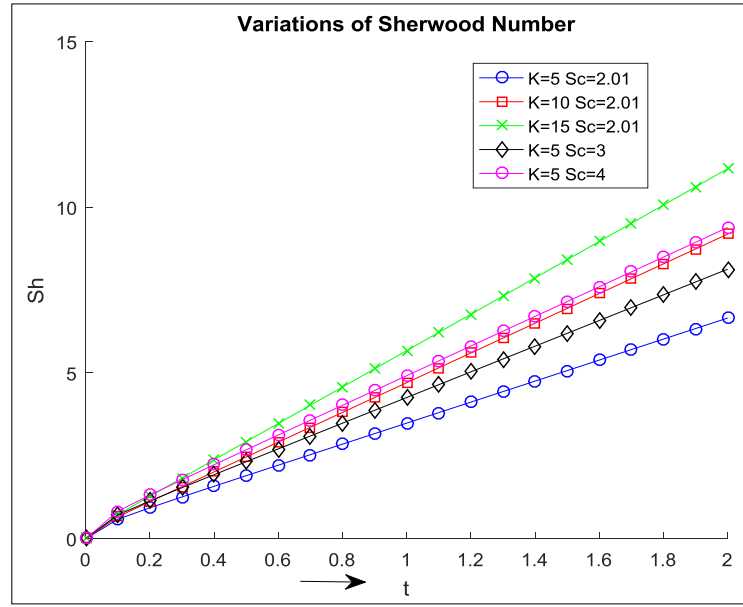

Fig.8 Effect of K and Sc on Sherwood Number
Skin-Friction variations at different parameters are shown by Figs. (9) - (11).

Fig. 9 represents graphically the effect of $\mathrm{M}$, a and Sc on Skin-Friction. The graph clearly depicts that accelerated parameter and magnetic field parameter increases the shear stress whereas mass diffusion has a reverse effect on it.

Fig. 10 represents graphically the effect of $\mathrm{K}$ and $\operatorname{Pr}$ on Skin-Friction. It is depicted that shear stress decreases with increase in $\mathrm{K}$ but it increases slightly Pr.

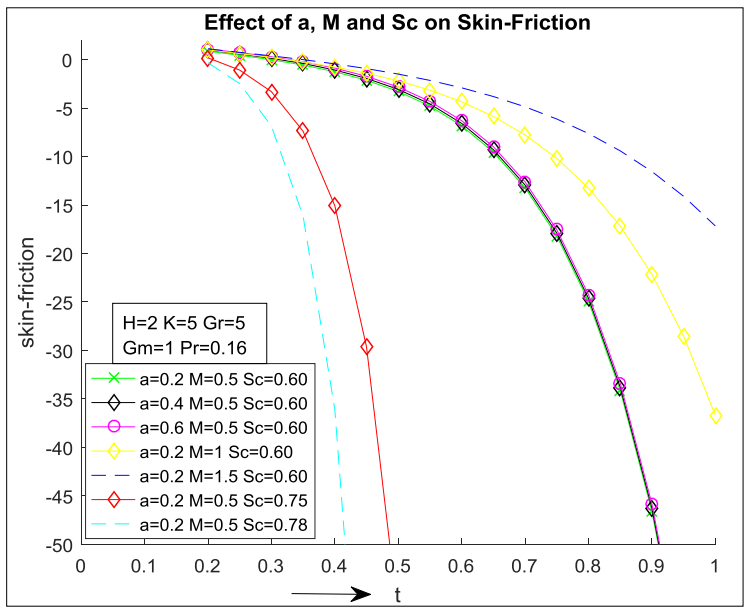

Fig.9 Effect of M, a and Sc on Skin-Friction

The effect of $\mathrm{H}, \mathrm{Gr}$ and $\mathrm{Gm}$ on Skin-Friction is represented in Fig. 11. It is evident from the graph that heat absorption parameter tend to increase the shear stress whereas thermal buoyancy forces and mass buoyancy forces have opposite effect on it.

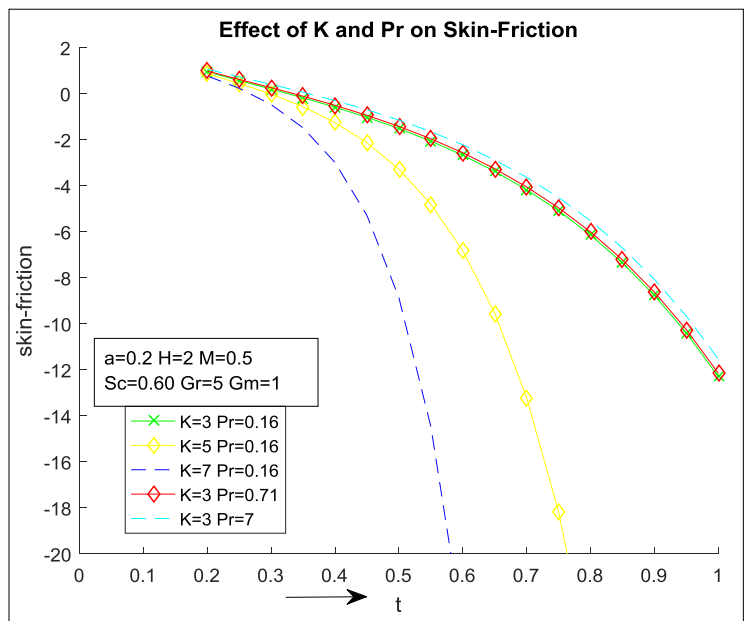

Fig.10 Effect of K and Pr on Skin Friction

Published By:

Blue Eyes Intelligence Engineering

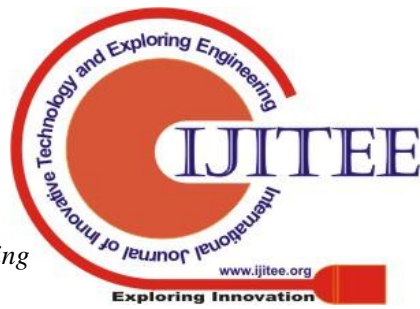




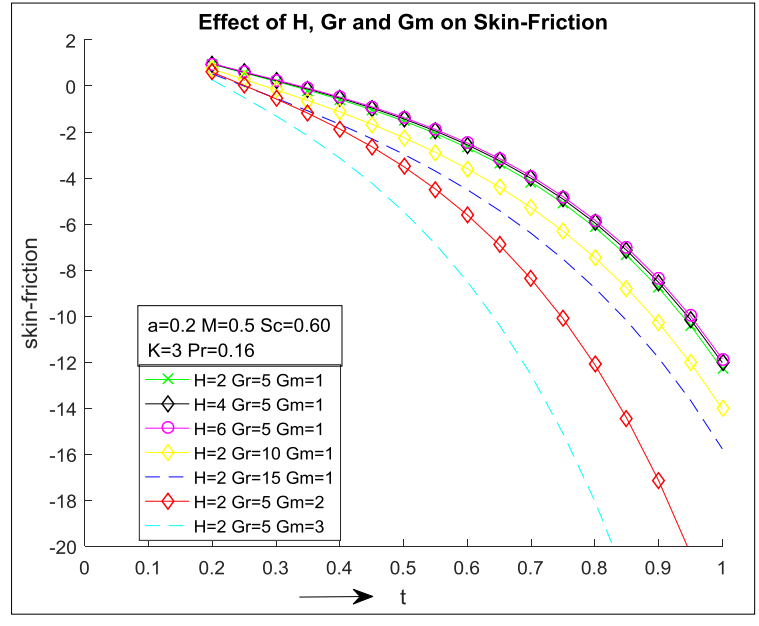

Fig.11 Effect of H, Gr and Gm on Skin Friction

\section{CONCLUSIONS}

The Present study can be concluded as:

-Heat absorption parameter and thermal diffusion reduces the fluid temperature while progression in time arises the temperature of the fluid.

-Progression in time increases the species concentration whereas Chemical reaction and mass diffusivity has reverse effect on it.

-Accelerated parameter and mass buoyancy forces accelerate the fluid motion whereas chemical reaction,

thermal buoyancy forces, heat absorption parameter,

magnetic field, , viscosity and mass diffusivity tends to retard the fluid motion.

-The heat transfer rate is increased with progression in time, thermal diffusion and heat absorption parameter.

-Rate of mass transfer increases with time, chemical reaction, and mass diffusivity.

-Shear stress increases with increment in accelerated parameter, thermal diffusion, heat absorption parameter and magnetic field parameter whereas heat time, mass diffusivity, chemical reaction parameter, thermal buoyancy forces and mass buoyancy forces decrease it.

\section{APPENDIX}

$\mathrm{l}=\frac{\mathrm{M}-\mathrm{H}}{\mathrm{P}_{\mathrm{r}}-1} \quad \mathrm{~m}=\frac{\mathrm{M}-\mathrm{KS}_{\mathrm{c}}}{\mathrm{S}_{\mathrm{g}}-1} \quad \mathrm{n}=\frac{\mathrm{G}_{\mathrm{r}}}{\mathrm{P}_{\mathrm{r}}-1} \quad \mathrm{p}=\frac{\mathrm{G}_{\mathrm{m}}}{\mathrm{S}_{\mathrm{e}}-1}$

$\mathrm{U}_{1}=\frac{\mathrm{n}}{21^{2}} \quad \mathrm{U}_{2}=\frac{\mathrm{p}^{\mathrm{f}}}{2 \mathrm{~m}^{2}} \quad \mathrm{U}_{\mathrm{a}}=\frac{\mathrm{n}}{\mathrm{l}} \quad \mathrm{U}_{4}=\frac{\mathrm{p}}{\mathrm{m}}$

$\gamma_{1}=$ at $\quad \gamma_{2}=$ lt $\quad \gamma_{a}=m t$

$\alpha_{1}=\mathrm{y} \sqrt{\mathrm{M}+\mathrm{a}} \quad \alpha_{2}=\mathrm{y} \sqrt{\mathrm{M}} \quad \alpha_{3}=\mathrm{y} \sqrt{\mathrm{M}+1}$

$\alpha_{4}=\mathrm{y} \sqrt{\mathrm{M}+\mathrm{m}}$

$\alpha_{5}=\mathrm{y} \sqrt{\mathrm{H}} \quad \alpha_{6}=\mathrm{y} \sqrt{\mathrm{H}+\mathbb{I P}_{\mathrm{r}}} \quad \alpha_{7}=\mathrm{y} \sqrt{\mathrm{KS}_{\mathrm{c}}}$

$\alpha_{\mathrm{g}}=\mathrm{y} \sqrt{(\mathrm{K}+\mathrm{m}) \mathrm{S}_{\mathrm{c}}}$

$\mathrm{C}_{1}=\frac{\mathrm{t}}{2}+\frac{\mathrm{y}}{4 \sqrt{\mathrm{M}}} \quad \mathrm{C}_{2}=\frac{\mathrm{t}}{2}-\frac{\mathrm{y}}{4 \sqrt{\mathrm{M}}} \quad \mathrm{C}_{\mathrm{a}}=\frac{\mathrm{t}}{2}+\frac{\mathrm{yP}}{4 \sqrt{\mathrm{H}}}$

$$
\begin{aligned}
& \mathrm{C}_{4}=\frac{\mathrm{t}}{2}-\frac{\mathrm{yP} \mathrm{P}_{\mathrm{r}}}{4 \mathrm{WH}} \\
& \mathrm{C}_{5}=\frac{\mathrm{t}}{2}+\frac{\mathrm{y} \sqrt{\mathrm{S}_{\mathrm{c}}}}{4 \sqrt{\mathrm{K}}} \quad \mathrm{C}_{6}=\frac{\mathrm{t}}{2}-\frac{\mathrm{y} \sqrt{\mathrm{S}_{\mathrm{c}}}}{4 \sqrt{\mathrm{K}}} \\
& \beta_{1}=\frac{y}{2 \sqrt{t}}+\sqrt{(\mathrm{M}+\mathrm{a}) \mathrm{t}} \quad \beta_{2}=\frac{y}{2 \sqrt{\mathrm{t}}}-\sqrt{(\mathrm{M}+\mathrm{a}) \mathrm{t}} \\
& \beta_{\mathrm{a}}=\frac{y}{2 \sqrt{\mathrm{t}}}+\sqrt{\mathrm{Mt}} \\
& \beta_{4}=\frac{y}{2 \sqrt{t}}-\sqrt{M t} \\
& \beta_{5}=\frac{y}{2 \sqrt{\mathrm{t}}}+\sqrt{(\mathrm{M}+\mathrm{l}) \mathrm{t}} \quad \beta_{6}=\frac{y}{2 \sqrt{\mathrm{t}}}-\sqrt{(\mathrm{M}+\mathrm{l}) \mathrm{t}} \\
& \beta_{7}=\frac{y}{2 \sqrt{t}}+\sqrt{(M+m) t} \quad \beta_{g}=\frac{y}{2 \sqrt{t}}-\sqrt{(M+m) t} \\
& \beta_{9}=\frac{y}{2 \sqrt{ } \mathrm{t}} \sqrt{\mathrm{P}_{\mathrm{r}}}+\sqrt{\frac{\mathrm{H}}{\mathrm{P}_{\mathrm{r}}} \mathrm{t}} \quad \beta_{10}=\frac{y}{2 \sqrt{\mathrm{t}}} \sqrt{\mathrm{P}_{\mathrm{r}}}-\sqrt{\frac{\mathrm{H}}{\mathrm{P}_{\mathrm{r}}} \mathrm{t}} \\
& \beta_{11}=\frac{y}{2 \sqrt{t}} \sqrt{P_{\mathrm{r}}}+\sqrt{\left(\frac{\mathrm{H}}{\mathrm{P}_{\mathrm{r}}}+1\right) \mathrm{t}} \quad \beta_{12}=\frac{y}{2 \sqrt{\mathrm{t}}} \sqrt{\mathrm{P}_{\mathrm{r}}}-\sqrt{\left(\frac{\mathrm{H}}{\mathrm{P}_{\mathrm{r}}}+1\right) \mathrm{t}} \\
& \beta_{1 \mathrm{a}}=\frac{y}{2 \sqrt{\mathrm{t}}} \sqrt{S_{\mathrm{c}}}+\sqrt{\mathrm{Kt}} \quad \beta_{14}=\frac{y}{2 \sqrt{\mathrm{t}}} \sqrt{S_{\mathrm{c}}}-\sqrt{\mathrm{Kt}} \\
& \beta_{15}=\frac{y}{2 \sqrt{t}} \sqrt{S_{c}}+\sqrt{(K+m) t} \\
& \beta_{16}=\frac{y}{2 \sqrt{t}} \sqrt{S_{c}}-\sqrt{(K+m) t}
\end{aligned}
$$

\section{ACKNOWLEDGMENT}

The authors are very thankful to IKGPTU, Kapurthala (Punjab), for providing the platform to do research work.

\section{REFERENCES}

1. G. G. Stokes, On the Effect of the Internal Fraction of Fluids on the Motion of a Pendulum Trans. Camb. Phil. Soc. 9, 1851, pp. 8-106.

2. A. Raptis and C. V. Massalas, Magnetohydrodynamic flow past a plate by the presence of radiation. Heat and Mass Transfer, 34, 1998, pp.107-109.

3. R. Muthucumaraswamy and P. Ganesan, Effect of the Chemical Reaction and Injection on Flow Characteristics in an Unsteady Upward Motion of an Isothermal Plate. J. Appl. Mech. Tech. Phys., 42, 2001, pp. 665-671.

4. V. M. Soundalgekar, N. S. Birajdar and V. K. Darwhekar, Mass transfer effects on the flow past an impulsively started infinite vertical plate with variable temperature or constant heat flux. Astrophysics and Space Science, 100, 1984, pp. 159-164.

5. A. K. Singh and N. Kumar, Free convection flow past an exponentially accelerated vertical plate. Astrophysics and Space science, 98,2000, pp. 245-258.

6. R. Muthucumaraswamy and V. Visalakshi, Radiative flow past an exponentially accelerated vertical plate with variable temperature and mass diffusion. Int. J. of Engg. Annals. of Faculty Engineering Hunedoara .Tom IX, Fascicule 2, 2008, pp. 137-140.

7. M. A Hossain., M. M. Molla and L. S. Yaa, Natural Convection Flow along a Vertical Wavy Surface Temperature in the Presence of Heat Generation/Absorption. Int. J. Thermal Sci., 43, 2004, pp. 157-163.

8. F. M. Hady, R. A. Mohamed and A. Mahdy, MHD Free Convection Flow along a Vertical Wavy Surface with Heat Generation or Absorption Effect. Int. Comm. Heat Mass Transfer, 33, 2006, pp. 1253-1263.

9. B. P. Garg and Shipra and N. Rani, Heat Source/Sink effect on Flow past an impulsively started vertical plate with variable heat and mass transfer. International Journal of Advance and Innovative Research, 6(1), 2019.

Published By:

Blue Eyes Intelligence Engineering

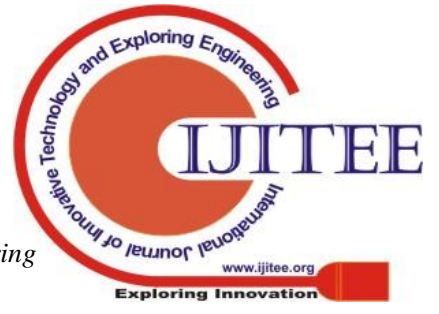




\section{AUTHORS PROFILE}

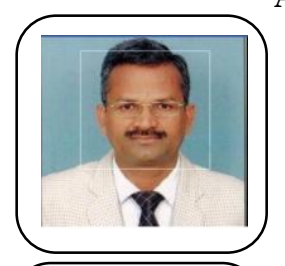

Dr. B.P. Garg is Research Supervisor at Department of Mathematical Sciences, IKGPTU, Kapurthala, Punjab, India. He is also Director of Adesh Institute of Engineering \& Technology, Faridkot.

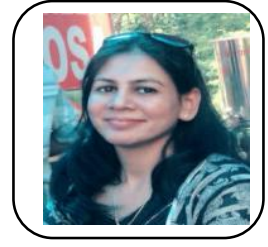

Shipra is a research scholar in Department of Mathematical Sciences of IKGPTU, Kapurthala, Punjab, India .She is also presently working as an Assistant Professor in Punjabi University College of Engineering and Management, Rampuraphul, Bathinda, Punjab (India).

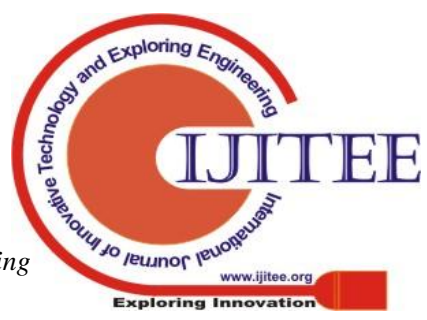

